\title{
Low volume, high frequency cows' milk feedings sped recovery from diarrhoea in infants
}

Wan C, Phillips MR, Dibley MJ, et al. Randomised trial of different rates of feeding in acute diarrhoea. Arch Dis Child 1999 Dec;81:487-91.

QUESTION: In infants with acute diarrhoea, do more frequent, low volume feedings of cows' milk promote faster recovery than less frequent, high volume feedings of the same total volume of cows' milk?

Design

14 day randomised (unclear allocation concealment*), unblinded,* controlled trial.

\section{Setting}

4 tertiary care hospitals in Chengdu, China.

\section{Patients}

282 boys who were $3-12$ months of age and had acute diarrhoea and mild to severe dehydration. Exclusion criteria were malnutrition, exclusive breast feeding, systematic infections (eg, pneumonia or septicaemia), or other diseases requiring additional treatments. Only boys were enrolled to facilitate the separation of urine and stool. 262 boys (93\%) (mean age $8 \mathrm{mo}$ ) completed the study.

\section{Intervention}

Infants were stratified by hospital and initial hydration status and allocated exclusively to cows' milk, either 18 $\mathrm{ml} / \mathrm{kg}$ of body weight every 3 hours over 18 waking hours ( 6 feeds/d [high volume] $)(\mathrm{n}=128)$ or $9 \mathrm{ml} / \mathrm{kg}$ every 1.5 hours over 18 waking hours (12 feeds/d [low volume]) $(\mathrm{n}=134)$.

\section{Main outcome measures}

Recovery from diarrhoea ( $2 \mathrm{~d}$ of formed stools at prediarrhoea frequency and $24 \mathrm{~h}$ stool weight $<30 \mathrm{~g} / \mathrm{kg}$ ) and treatment failure (dehydration $>5 \%$ of body weight after third day of admission, serious complications, persistent electrolyte abnormalities, prolonged severe diarrhoea, or diarrhoea continuing after 14 days of treatment).

\section{Main results}

Source of funding: International Clinical Epidemiology Network (INCLEN).

For correspondence: Dr C Wan,

Departments of

Pediatrics and Clinical Epidemiology, West China University of

Medical Sciences,

Chengdu 610041,

People's Republic of China.
All but 1 infant in the low volume group had recovered from diarrhoea by day 14; no infants in either group met criteria for treatment failure. Kaplan-Meier analysis showed that the low volume group had a more rapid recovery from diarrhoea than the high volume group. After adjusting for age, dehydration status on admission, and cause of diarrhoea, the rate of recovery from diarrhoea was $29 \%$ higher in the low volume group than in the high volume group (hazard ratio 1.29, 95\% CI 1.00 to $1.65, \mathrm{p}=0.048)$. The increase in body weight was faster in the low volume group $(\mathrm{p}=0.012)$, and average stool frequency and stool weight from the second to fifth day of treatment were lower $(p \leqslant 0.027)$.

\section{Conclusion}

In infants with acute diarrhoea, feedings of cows' milk 12 times per day promoted faster recovery than the same total volume of cows' milk given 6 times per day.

*See glossary.

\section{COMMENTARY}

Diarrhoea accounts for one third of infant and child deaths worldwide. Although widespread use of oral rehydration treatment has reduced deaths by one third, 2 million children still die of diarrhoea each year. ${ }^{1}$ Even uncomplicated diarrhoea causes considerable weight loss, which results in a substantially lower level of nutrition than that in the prediarrhoeal state. The effect of diarrhoea is worsened by the custom of starving the child to give rest to the gut and by the child's poor appetite. Early feeding as soon as dehydration is corrected is advised to prevent weight loss. ${ }^{2}$ However, an injured gut may not tolerate full strength milk, especially in young infants. Recurring diarrhoea has been attributed to lactose intolerance, ${ }^{3}$ and has led to the recommendation of diluting milk to reduce the risk for intolerance. However, a well done randomised controlled trial has shown that diluting milk does not reduce complications. ${ }^{4}$

The study by Wan $e t$ al provides an appealing solution. It has proved convincingly that small, frequent feedings result in quicker restoration of the prediarrhoeal nutritional status. We know intuitively that the low volume, frequent feedings are less likely to burden the functioning of a diseased gut.

Many of the study limitations have been pointed out by the authors. However, the outcome measures were reasonably objective. If the results of this study can be repeated, milk can be given with oral rehydration salt solutions, and the need for intravenous rehydration and admission to hospital can be minimised. More randomised trials are needed in this area using different types and dilutions of feeds. Manjula Datta, MD, DCH, MSc Tamil Nadu Dr MGR Medical University Chennai, Tamil Nadu, India

1 Bellamy C. The state of the world's children. UNICEF; 1998. http://www.unicef.org/sowc98/sw98rite.htm.

2 Brown KH. Dietary management of acute childhood diarrhea: optimal timing of feeding and appropriate use of milks and mixed diets. J Pediatr 1991;118:S92-8.

3 Trounce JQ Walker-Smith JA. Sugar intolerance complicating acute gastroenteritis. Arch Dis Child 1985;60:986-90.

4 Chew F, Penna FJ, Peret Filho LA, et al. Is dilution of cows' milk formula necessary for dietary management of acute diarrhoea in infants aged less than 6 months? Lancet 1993;341:194-7. 